\title{
EDITORIAL
}

\section{Tumour-associated macrophages in nonsmall cell lung cancer: the role of interleukin-10}

\author{
L.M. Montuenga*,\# and R. Pio*,
}

$\mathbf{T}$ he origin, progression and dissemination of solid tumours are strongly regulated by stromal, endothelial or defence-related cells [1]. Tumour cells do not merely grow into an inert interstitial tissue, but they actively interact with their microenvironment establishing cell-to-cell contacts, releasing soluble factors and responding to soluble factors released by neighbouring cells. In recent years, evidence has been accumulated to support a dual role for macrophages in the regulation of tumour cell proliferation, invasion, angiogenesis or immune control [2, 3]. On one hand, the "resident" tissue macrophages have a cytotoxic function against tumour development as they are a major component of the inflammatory infiltrate frequently seen in primary tumours. On the other hand, a different phenotype of monocyte-derived "tumour-associated macrophages" (TAMs) shows opposite behaviour with a commonly pro-tumoral phenotype. The ability of macrophages to promote or inhibit neoplasia seems to depend on their differentiation and activation states $[4,5]$. At least two major functional states have been described for macrophages and named as M1 and M2. Classically activated M1 macrophages are induced by interferon- $\gamma$ alone or in combination with lipopolysaccharide and tumour necrosis factor- $\alpha$. M1 macrophages produce high levels of inducible nitric oxide synthase and pro-inflammatory cytokines, such as interleukin (IL)-12, and are generally considered as part of the inflammatory response against cancer progression. In contrast, M2 macrophages express arginase I, promote angiogenesis, favour tissue remodelling and invasion, and are able to inhibit the inflammatory response through the secretion of IL-10. Thus M2 macrophages are thought to exert a tumour-promoting activity. In most of the solid tumour types that have been analysed so far, TAMs show an M2 differentiation profile, correlate with microvessel density and are associated with reduced patient survival. REDENTE et al. [6] have recently published a detailed analysis of the changes in activation state

*Division of Oncology (CIMA), Depts of \#Histology and Pathology and "Biochemistry, University of Navarra, Pamplona, Spain.

SUPPORT STATEMENT: The work carried out by the authors is supported by the UTE-CIMA agreement project, Spanish Ministry of Health (ISCIII: RTICC, FIS-PI 04/2128), "Mutua Madrileña" Medical Research Council (FMM), Spanish Ministry of Education (SAF2005-01302) and the Depts of Health and Education of the Government of Navarra.

STATEMENT OF INTEREST: None declared

CORRESPONDENCE: L.M. Montuenga, Division of Oncology, CIMA Building, University of Navarra, Pio XII 55, 31008 Pamplona, Spain. Fax: 34 948194714. E-mail: Imontuenga@unav.es of macrophages during neoplastic progression in a well-known experimental lung cancer mouse model. Previous studies on the association of tumour infiltration by macrophages and the survival of patients with surgically resected nonsmall cell lung cancer (NSCLC) have rendered conflicting results. The prognostic value of macrophages in NSCLC seems to depend on their microanatomical distribution (within tumour islets or in the stroma) [7]. Macrophage activation states have not been examined yet in human lung carcinogenesis.

The study by ZENI et al. [8] in the present issue of the European Respiratory Journal studies the expression of IL-10 in human NSCLC focusing on both TAMs and tumour cells. IL-10 has been previously shown in NSCLC tissue homogenates [9] and is elevated in the serum of NSCLC patients [10]. ZENI et al. [8] examine whether the expression of IL-10 in NSCLC cells and TAMs can be correlated with clinicopathological features of the patients. In total, 50 NSCLC patients (34 adenocarcinomas and 16 squamous cell carcinomas) were included; approximately half of the patients were classified as stage I and the remaining as stage II-IV. Samples from surgically resected tumours were analysed for IL-10 expression by immunocytochemistry. Although the density of macrophages was not different between early and late stages, the authors observed a significant increase of IL-10 positive TAMs in tumour specimens from patients with stage II-IV when compared with patients with stage I. Interestingly, IL-10 expression in TAMs was associated with shorter overall patient survival, although it did not prove to be an independent prognosis factor. Previous studies have already suggested the prognostic value of IL-10 expressed by TAMs in other malignancies [11].

In contrast to what ZENI et al. [8] found in TAMs, no difference in IL-10 expression was detected in tumour cells among stages. The prognostic significance of IL-10 expression in lung tumour tissues has rendered controversial results in the past. HATANAKA et al. [12] reported that NSCLC patients with high IL-10 expressing tumours showed poorer prognosis than those without IL-10 expression. Previously, SORIA et al. [13] had reported that stage-I NSCLC patients with tumours lacking IL10 expression had worse prognosis than those with IL-10 expression. Major differences in the design of the three studies may explain this inconsistency. HATANAKA et al. [12] evaluated IL-10 expression by reverse transcriptase-PCR in 82 patients with stage I-III NSCLC. ZENI et al. [8], however, applied immunohistochemistry to 50 stage I-IV cases. Finally, SORIA et al. [13] used a different antibody for immunocytochemical localisation of IL-10 and focused on a more homogeneous 
population of 138 stage I patients. Therefore, the strikingly contrasting conclusions are probably due to both technical differences and, very likely, to the specific biology of stage I early lung tumours [13] as compared with more advanced II-IV stages, also studied by HATANAKA et al. [12] and ZENI et al. [8].

Besides lung tumours, overexpression of IL-10 in serum or peritumoral stroma has been reported in several other malignancies: melanoma [14]; cutaneous basal and squamous cell carcinomas [15]; ovarian carcinoma [16]; head and neck squamous cell carcinoma [17]; brain tumours [18]; and colorectal carcinoma [19]. IL-10 is thought to suppress immune and inflammatory responses; it inhibits the tumoricidal capacity of macrophages, tampers with the cytotoxicity and cytokine production of tumour-specific T-cells and blocks the presentation of antigens by antigen-presenting cells [20]. Production of IL-10 may provide a mechanism for the tumour to evade the local T-cell-mediated immune response [15]. In lung carcinomas, IL-10 production can inhibit tumour cell susceptibility to cytotoxic T-lymphocyte-mediated killing [21]. IL-10 transgenic mice injected with Lewis lung carcinoma cells developed larger tumours than control mice, suggesting that the production of IL-10 prevents the development of an effective immune response against the tumour cells [22]. In summary, the classical view is that IL-10-mediated downregulation of the host's immune system may allow immunogenic tumours to escape immunosurveillance and promote tumorigenesis. From the clinical point of view, this role of IL-10 in cancer leads to the assumption that high IL-10 production by a tumour may limit the success of lung cancer immunotherapy. However, the situation seems to be more complex, and the real role of IL-10 in cancer is far from being completely elucidated. An increasing number of studies show that IL-10 has pleiotropic biological activities, including immunostimulatory and antineoplastic effects [23]. Some in vivo studies have suggested that IL-10 might inhibit tumour growth and metastasis in murine models [24-28]. Even IL-10 knockout models have yielded opposite results in different experimental situations: B-cell tumours in IL-10 null mice grow slower than controls [29] but IL-10-deficient mice develop colitis-associated colorectal carcinoma [30]. In fact, although it is commonly regarded as an antiinflammatory, immunosuppressive cytokine, IL-10 also possesses immunostimulating properties [23]. These conflicting biological data may explain the contradictory results found on the prognostic relevance of IL-10 expressed by lung cancer cells $[8,12,13,31]$.

It is evident that further efforts should be made to clarify the implication of IL-10 in lung tumour development, first at the basic carcinogenesis level with cell and animal models and eventually in the clinical setting. In this sense, the association between IL-10 gene promoter polymorphisms and cancer susceptibility and progression is also an interesting field of research [32]. SHIH et al. [33] have reported that certain genotypes associated with higher IL-10 production can increase the susceptibility to NSCLC. This association must be confirmed in independent and larger cohorts of NSCLC patients. To date, no study on the association between IL-10 genotype and prognosis of lung cancer has been reported. There are also many questions left open by the data provided by ZENI et al. [8]. It is striking that they have found differences among stages in the expression of IL-10 by macrophages but not by tumoural cells. Does it mean that the potential regulation by IL-10 depends more on the macrophages than on the tumour cells? The field of TAMs is still in its infancy. Unfortunately, most of the studies have been carried out in tumours other than lung cancer. Data generated in other organs need to be validated in the lung, and specific lungrelated questions need to be addressed. Two examples are as follows. 1) Do alveolar macrophages change their phenotype upon stimulation by peripheral tumour cells or are they monocyte-derived cells recruited from the circulation? 2) Would the IL-10 levels in macrophages from bronchoalveolar lavage be a useful prognostic tool for NSCLC patients?

Understanding the interplay between inflammatory and tumour cells in lung cancer will permit the development of new cancer therapeutic strategies aimed to modulate the interaction between tumour and stromal cells. If the immunosuppressive effect of interleukin-10 in nonsmall cell lung cancer is confirmed, strategies to inhibit its effect should be evaluated. The elucidation of the mechanisms by which tumour-associated macrophages cooperate with tumour growth will also aid in the design of approaches to boost anti-tumour immunity. To date, there are still fragmentary and even contradictory results on the role of interleukin-10 and tumour-associated macrophages in lung cancer progression. Studies, such as the one by ZENI et al. [8], are needed to progress knowledge about the association between inflammation and lung cancer.

\section{REFERENCES}

1 Hanahan D, Weinberg RA. The hallmarks of cancer. Cell 2000; 100: 57-70.

2 Kataki A, Scheid P, Piet M, et al. Tumor infiltrating lymphocytes and macrophages have a potential dual role in lung cancer by supporting both host-defense and tumor progression. J Lab Clin Med 2002; 140: 320-328.

3 Lewis CE, Pollard JW. Distinct role of macrophages in different tumor microenvironments. Cancer Res 2006; 66: 605-612.

4 Mantovani A, Schioppa T, Porta C, Allavena P, Sica A. Role of tumor-associated macrophages in tumor progression and invasion. Cancer Metastasis Rev 2006; 25: 315-322.

5 Mantovani A, Sica A, Locati M. New vistas on macrophage differentiation and activation. Eur J Immunol 2007; 37: 14-16.

6 Redente EF, Orlicky DJ, Bouchard RJ, Malkinson AM. Tumor signaling to the bone marrow changes the phenotype of monocytes and pulmonary macrophages during urethane-induced primary lung tumorigenesis in A/J mice. Am J Pathol 2007; 170: 693-708.

7 Welsh TJ, Green RH, Richardson D, Waller DA, O'Byrne KJ, Bradding P. Macrophage and mast-cell invasion of tumor cell islets confers a marked survival advantage in non-small-cell lung cancer. J Clin Oncol 2005; 23: 8959-8967.

8 Zeni E, Mazzetti L, Miotto D, et al. Macrophage expression of interleukin-10 is a prognostic factor in nonsmall cell lung cancer. Eur Respir J 2007; 30: 627-632.

9 Huang M, Wang J, Lee $\mathrm{P}$, et al. Human non-small cell lung cancer cells express a type 2 cytokine pattern. Cancer Res 1995; 55: 3847-3853. 
10 De Vita F, Orditura M, Galizia G, et al. Serum interleukin10 levels as a prognostic factor in advanced non-small cell lung cancer patients. Chest 2000; 117: 365-373.

11 Wagner S, Czub S, Greif M, et al. Microglial/macrophage expression of interleukin 10 in human glioblastomas. Int J Cancer 1999; 82: 12-16.

12 Hatanaka H, Abe Y, Kamiya T, et al. Clinical implications of interleukin (IL)-10 induced by non-small-cell lung cancer. Ann Oncol 2000; 11: 815-819.

13 Soria JC, Moon C, Kemp BL, et al. Lack of interleukin-10 expression could predict poor outcome in patients with stage I non-small cell lung cancer. Clin Cancer Res 2003; 9: 1785-1791.

14 Nemunaitis J, Fong T, Shabe P, Martineau D, Ando D. Comparison of serum interleukin-10 (IL-10) levels between normal volunteers and patients with advanced melanoma. Cancer Invest 2001; 19: 239-247.

15 Kim J, Modlin RL, Moy RL, et al. IL-10 production in cutaneous basal and squamous cell carcinomas. A mechanism for evading the local $\mathrm{T}$ cell immune response. J Immunol 1995; 155: 2240-2247.

16 Gotlieb WH, Abrams JS, Watson JM, Velu TJ, Berek JS, Martínez-Maza O. Presence of interleukin 10 (IL-10) in the ascites of patients with ovarian and other intra-abdominal cancers. Cytokine 1992; 4: 385-390.

17 Jebreel A, Mistry D, Loke D, et al. Investigation of interleukin 10, 12 and 18 levels in patients with head and neck cancer. J Laryngol Otol 2007; 121: 246-252.

18 Zhang L, Handel MV, Schartner JM, et al. Regulation of IL10 expression by upstream stimulating factor (USF-1) in glioma-associated microglia. I Neuroimmunol 2007; 184: 188-197.

19 Evans C, Dalgleish AG, Kumar D. Review article: immune suppression and colorectal cancer. Aliment Pharmacol Ther 2006; 24: 1163-1177.

20 de Waal Malefyt R, Yssel H, Roncarolo MG, Spits H, de Vries JE. Interleukin-10. Curr Opin Immunol 1992; 4: 314-320.

21 Asselin-Paturel C, Megherat S, Vergnon I, et al. Differential effect of high doses versus low doses of interleukin-12 on the adoptive transfer of human specific cytotoxic $\mathrm{T}$ lymphocyte in autologous lung tumors engrafted into severe combined immunodeficiency disease-nonobese diabetic mice: relation with interleukin-10 induction. Cancer 2001; 91: 113-122.
22 Hagenbaugh A, Sharma S, Dubinett SM, et al. Altered immune responses in interleukin 10 transgenic mice. J Exp Med 1997; 185: 2101-2110.

23 Mocellin S, Marincola FM, Young HA. Interleukin-10 and the immune response against cancer: a counterpoint. J Leukoc Biol 2005; 78: 1043-1051.

24 Giovarelli M, Musiani P, Modesti A, et al. Local release of IL-10 by transfected mouse mammary adenocarcinoma cells does not suppress but enhances antitumor reaction and elicits a strong cytotoxic lymphocyte and antibodydependent immune memory. J Immunol 1995; 155: 3112-3123.

25 Huang S, Xie K, Bucana CD, Ullrich SE, Bar-Eli M. Interleukin 10 suppresses tumor growth and metastasis of human melanoma cells: potential inhibition of angiogenesis. Clin Cancer Res 1996; 2: 1969-1979.

26 Zheng LM, Ojcius DM, Garaud F, et al. Interleukin-10 inhibits tumor metastasis through an NK cell-dependent mechanism. J Exp Med 1996; 184: 579-584.

27 Kundu N, Beaty TL, Jackson MJ, Fulton AM. Antimetastatic and antitumor activities of interleukin 10 in a murine model of breast cancer. J Natl Cancer Inst 1996; 88: 536-541.

28 Berman RM, Suzuki T, Tahara H, Robbins PD, Narula SK, Lotze MT. Systemic administration of cellular IL-10 induces an effective, specific, and long-lived immune response against established tumors in mice. I Immunol 1996; 157: 231-238.

29 Czarneski J, Lin YC, Chong S, et al. Studies in NZB IL-10 knockout mice of the requirement of IL-10 for progression of B-cell lymphoma. Leukemia 2004; 18: 597-606.

30 Sturlan S, Oberhuber G, Beinhauer BG, et al. Interleukin-10deficient mice and inflammatory bowel disease associated cancer development. Carcinogenesis 2001; 22: 665-671.

31 Neuner A, Schindel M, Wildenberg U, Muley T, Lahm H, Fischer JR. Prognostic significance of cytokine modulation in non-small cell lung cancer. Int J Cancer 2002; 101: 287-292.

32 Howell WM, Rose-Zerilli MJ. Interleukin-10 polymorphisms, cancer susceptibility and prognosis. Fam Cancer 2006; 5: 143-149.

33 Shih CM, Lee YL, Chiou HL, et al. The involvement of genetic polymorphism of IL-10 promoter in non-small cell lung cancer. Lung Cancer 2005; 50: 291-297. 